\title{
French study sparks debate on informed consent laws
}

Paris. French researchers are calling for reform of laws on medical confidentiality, data protection and free and informed consent better to meet the needs of science following allegations in the press against a government research group.

The controversy involves a study by Christiane Capron, Michel Duyme and Michele Carlier in the laboratory of Pierre Roubertoux at the Centre National de la Recherche Scientifique (CNRS)/University of Paris V Reneé Descartes Laboratory of Genetics, Neurogenetics and Behaviour in Paris. Building on work with adopted children (see Nature 340, 552; 1989), the team assessed the pre- and post-natal effects of artificial insemination on the cognitive abilities of children with the same father to test whether assisted procreation itself could cause harmful neurological or psychological effects. Such effects have been found in mice.

Capron's group obtained from the operator of a private sperm bank, Sacha Geller, the names of 120 children born after artificial insemination. Geller is a controversial figure who created an agency for surrogate mothers (since banned) and who advocates artificial insemination as a way for single mothers and lesbians to have children. The CNRS group subsequently tested the cognitive abilities of the 120 children and 3,600 of their classmates.

L'Express magazine alleged in two stories last month that the researchers have contravened three laws - one forbidding doctors from telling anyone except another doctor about a patient, and then only if the information is used for therapeutic purposes; one protecting the confidentiality of data; and one requiring people involved in such matters to give their informed consent. The allegations have since been taken up by other media.

Claude Paoletti, director of life sciences at the CNRS, says that existing laws place researchers in a bind. At present, he says, a researcher's conscience and in-house ethics codes have been accepted as an adequate substitute for flaws in legislation; many scientists would find themselves breaking those laws, he maintains, if they were stringently enforced.

The former president of the national bioethics advisory committee, Jean Bernard, illustrates the dilemma facing researchers by citing the example of those who use epidemiological research to diagnose diseases with several causes but who, to do so, must first obtain the names of individuals. Paoletti says that similar problems arise whenever medical and basic research overlap and suggests that "there should be a law allowing researchers to access medical information without breaking the law".

There may be progress on this front. A bioethics bill (see Nature 356, 368; 1992) would for the first time allow medical information to be used for research with approval from a new committee. But the bill relates only to epidemiological research; scientists want legislation covering all relevant research.

The press reports also allege that the CNRS researchers did not have the free and informed consent of the children's parents. The letter sent to parents and teachers mentioned cognitive studies but not their precise aims. The requirement for such permission comes from a 1988 law designed for clinical trials, and scientists have questioned its relevance to research where the subject is not likely to be harmed.

Duyme says that the group did not seek the consent of parents because it would have "worried them unnecessarily". At the same time, he points out, the entire class was tested to preserve the anonymity of those being studied, following a protocol first approved in 1972 by the Ministry of Health.

Researchers perceive the controversy quite differently from the media. L'Express,

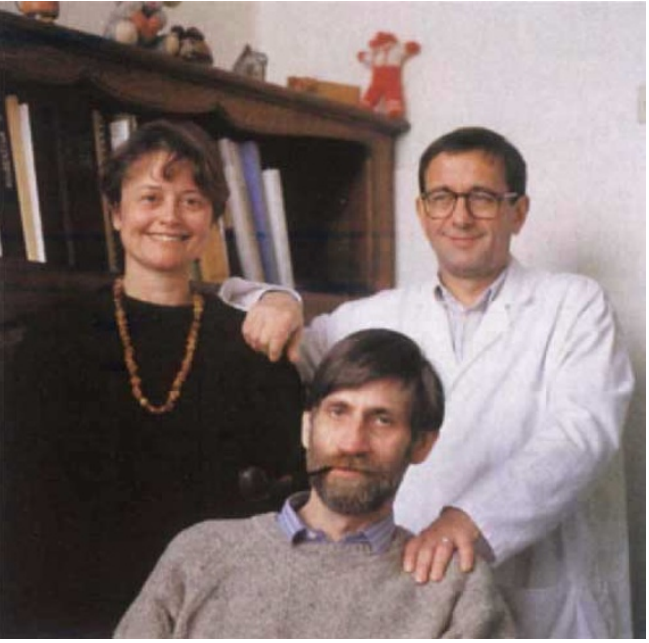

Carlier, Duyme and Roubertoux (from left) are at the center of controversy.

for example, portrayed the breach of confidentiality as a new and dangerous form of malpractice and its failure to obtain informed consent as deliberate subterfuge. But the author acknowledges that his perspective is coloured by his vociferous opposition to work on the genetic bases of human behaviour.

The controversy threatens to disrupt future research in the CNRS laboratory. In the meantime, French scientists are concerned that media review could be taking the place of peer review in judging the quality of their work.

Declan Butler

\section{Medical council of Canada broadens role}

Quebec. The role of the Medical Research Council (MRC) of Canada will be greatly expanded during the next five years, evolving from the country's major funding body for biomedical research to the "voice of the health sciences" in Canada.

In a strategic plan released this month, the MRC proposes to support research not just in traditional biomedical research areas such as basic biology, mechanisms of prevention, diagnosis and treatment and clinical trials but also in such subjects as the socioeconomic factors of illness, outcomes and cost-effectiveness of medical interventions and bioethics. The agency will seek partnerships with industry, in particular with the C $\$ 6$-billion (US $\$ 4.5$ billion) pharmaceutical industry (see Nature 359, 351; 1992) and with those producing medical devices, computer software, electronics and chemicals.

MRC's new vision will require striking a balance between targeting research priorities and supporting investigator-initiated research. It will involve improved support for students, development of new classes of associates and awards and training programmes to increase the number of women and minorities in the field. Current programmes will be evaluated, the peer review process reviewed and administration improved. Better procedures will be developed to communicate research results and to advertise the achievements of Canadian science. Attempts will be made to attract more funding for health research, including private support from organizations outside Canada.

The strategic plan grew out of what MRC president Henry Friesen has called "the most thorough self-appraisal in our history". That assessment was necessary, he said, because of the vast changes in recent years in biomedical research. The process involved more than 3,000 researchers and health administrators attending a series of meetings over five months that ended last May in their endorsement of an expanded role for the council.

In the end, most participants felt that the council had no choice but to expand its scope. As Mamoru Watanabe, dean of medicine at the University of Calgary, remarked: "If the MRC does not get involved [in these issues], it will not survive".

David Spurgeon 